\title{
ORGANIZAÇÃO SOCIAL DOS ANIMAIS: UM FASCINANTE ESTUDO ETOLÓGICO
}

\author{
Letícia Hoehne ${ }^{1}$, Nêmora Pauletti Prestes², Cláudia Regina Pilonetto ${ }^{3}$
}

\begin{abstract}
Resumo: Etologia é uma ciência desconhecida por muitos, fato que promove curiosidade. Mas desde a época em que o homem surgiu na Terra, houve a necessidade de conhecer e estudar os animais a sua volta, para garantir a sua sobrevivência. Hoje em dia, a Etologia é muito mais abrangente, ganhando cunho científico, passou de ser apenas garantia de sobrevivência do homem, para meio de permanência e manutenção de todas as espécies do planeta. Com isso, este artigo reúne informações acerca da história da Etologia, seguido por explanações sobre as mais diversas organizações sociais existentes entre os animais e como ocorre um equilíbrio harmonioso dentro delas, o qual promove a manutenção natural da biodiversidade. Também, destaca a importância da educação ambiental como aliada para a conservação de espécies, uma vez que a escola tem poder de formar cidadãos atuantes em prol do bem comum, relacionando todas as formas de vida.
\end{abstract}

Palavras-chave: Biodiversidade. Comportamento animal. Educação ambiental.

1 Graduação em Ciências Biológicas pela Universidade de Passo Fundo, Especialização em Biologia da Conversação da Natureza pela Universidade de Passo Fundo, Especialização em Educação Ambiental pelo Centro Universitário Barão de Mauá, São Paulo. Professora de Ciências na Escola Estadual de Ensino Fundamental Justino Alberto Tietboehl, no município de Torres/RS.

2 Graduação em Ciências pela Universidade de Passo Fundo (1983), habilitação em Biologia pela Universidade de Passo Fundo (1985), mestrado em Biociências (Zoologia) pela Pontifícia Universidade Católica do Rio Grande do Sul (1996) e doutorado em Biociências (Zoologia) pela Pontifícia Universidade Católica do Rio Grande do Sul (2003). Atualmente é professora titular dos cursos de Ciências Biológicas (Licenciatura e Bacharelado) e do Programa de Pós-Graduação em Ciências Ambientais da Universidade de Passo Fundo. Consultora ad-hoc da Fundação O Boticário de Proteção à Natureza e membro sócio da Associação Amigos do Meio Ambiente (AMA). Faz parte do Grupo Assessor para acompanhar a implementação e realizar monitoria do Plano de Ação Nacional para a Conservação dos Papagaios da Mata Atlântica ? PAN Papagaios (CEMAVE/ICMBio). Tem experiência na área de Zoologia, com ênfase em Comportamento Animal, atuando principalmente nos seguintes temas: ecologia, comportamento e conservação de aves, biologia da conservação e unidades de conservação.

3 Graduação em Ciências Biológicas pela Universidade de Passo Fundo. 


\title{
SOCIAL ORGANIZATION OF ANIMALS: A FASCINATING ETHOLOGICAL STUDY
}

\begin{abstract}
Ethology is a science unknown to many, a fact that promotes curiosity. But since the time that man appeared on Earth, there was a need to know and study the animals around him to ensure their survival. Nowadays, ethology is much more comprehensive, gaining a scientific edge, from being only a guarantee of man's survival, to the means of permanence and maintenance of all species on the planet. Thus, this article gathers information about the history of ethology, followed by explanations about the most diverse social organizations among animals and how a harmonious balance occurs within them, which promotes the natural maintenance of biodiversity. It also highlights the importance of environmental education as an ally for the conservation of species, since the school has the power to form citizens acting for the common good, relating all forms of life.
\end{abstract}

Keywords: Biodiversity. Animal behavior. Environmental education.

\section{INTRODUÇÃO}

Etologia é uma especialidade que estuda o comportamento animal. Desde a época em que o homem surgiu na Terra, houve a necessidade de conhecer e estudar os animais a sua volta, para garantir a sua sobrevivência. Hoje em dia, a Etologia é muito mais abrangente, ganhando cunho científico, passou de ser apenas garantia de sobrevivência do homem, para meio de permanência e manutenção de todas as espécies do planeta.

Foi então, a partir de observações empíricas ou propositais, que se percebeu animais que viviam solitários, encontrando um par apenas para o acasalamento, já outros, que permaneciam em grupos durante todas as estações do ano. Mas de que maneira esses grupos eram estabelecidos? Quais fatores influenciavam na organização social das mais variadas espécies? Qual é a importância destas informações? Abstêm-se, inicialmente, que é fundamental conhecer uma espécie para conservá-la.

Com isso, este artigo reúne informações acerca da história da Etologia, seguido por explanações sobre as mais diversas organizações sociais existentes entre os animais e como ocorre um equilíbrio harmonioso dentro delas, o qual promove a manutenção natural da biodiversidade. Também, destaca-se a importância da educação ambiental como aliada para a conservação de espécies, uma vez que a escola tem poder de formar cidadãos atuantes em prol do bem comum, relacionando todas as formas de vida.

\section{ETOLOGIA: A CIÊNCIA DAS INDAGAÇÕES}

O termo Etologia, o qual deriva do grego Ethos, que significa hábito, costume, apareceu pela primeira vez em publicações da Academia Francesa de Ciências, por volta da metade do século XVIII com o objetivo de descrição de estilos de vida (DEL-CLARO, 2003). No entanto, este assunto é estudado atualmente em ecologia. Considera-se a forma como foi utilizada por Niko Tinbergen, em 1950, como 
correspondente à empregada hoje, exclusivamente para o estudo do comportamento animal.

O comportamento animal trata-se de algo que motiva o ser humano a milhares de anos pelos mais diversos interesses, desde o intuito de caçar e alimentar-se, protegerse ou domesticar para diversos fins, como para auxílio no transporte, na agricultura rudimentar e no incomparável companheirismo. Para a concretização de tais objetivos, foi necessário que o homem aprendesse a observá-los e estudá-los.

Atualmente, a pesquisa sobre o comportamento animal vai além da necessidade humana. O pesquisador Carthy (1980) define comportamento animal como aquilo que percebemos das reações de um animal ao ambiente que o cerca e que são, por sua vez, influenciadas por fatores internos variáveis, e Del-Claro (2003) delibera como sendo todo e qualquer ato executado por um animal, perceptível ou não, ao universo sensorial humano. $\mathrm{O}$ fato é que se trata de algo, indiscutivelmente, encantador por vários motivos.

Niko Tingergen, Konrad Lorenz e Karl Von Frish são considerados destaques no estudo da Etologia, pois abriram "portas" para pesquisas e publicações científicas nesta área do conhecimento, especialmente após receberem o prêmio Nobel, juntos, em 1973, na categoria Fisiologia e Medicina (DEL-CLARO, 2003). Compromissados pesquisadores, os três cientistas procuravam explicar como ocorria determinado comportamento, buscando entender as motivações internas e externas que desencadeavam em tal decisão. Devido a isto, Tinbergen ficou conhecido por formular as quatro questões sobre o comportamento, as quais a Etologia é caracterizada por responder: sua causalidade imediata, seu desenvolvimento ontogenético, sua função e seu significado adaptativo (CARRANZA, 1994).

As respostas das quatro questões são complementares, para, de fato, compreender o comportamento. Krebs e Davies (1996) apresentam um exemplo para responder por que as aves, popularmente conhecida como estorninhos, cantam na primavera:

1. Em termos de valor de sobrevivência ou função. Os estorninhos cantam para atrair parceiros para o acasalamento.

2. Em termos de causalidade. Porque o aumento no comprimento do dia desencadeia mudanças nos níveis hormonais, ou pela maneira em que o ar flui através da siringe e provoca vibrações na membrana. Estas são respostas sobre os fatores externos e internos que levam os estorninhos a cantarem.

3. Em termos de desenvolvimento. Os estorninhos cantam porque eles aprenderam os cantos de seus pais e vizinhos.

4. Em termos de história evolutiva. Esta resposta seria sobre como o canto evoluiu nos estorninhos a partir de seus ancestrais. Os pássaros vivos mais primitivos emitem sons muito simples, portanto é razoável supor que o canto complexo dos estorninhos e de outros pássaros tenha evoluído a partir de chamados ancestrais mais simples (KREBS; DAVIES, 1996) 
A partir de então, o interesse nesta área da ciência só aumentou, e proporcionou avanços significativos na compreensão da relação comportamento animal, ecologia e evolução (KREBS; DAVIES, 1996), para estudos da sociedade humana, neurobiologia, educação em ciências, bem estar animal, conservação e manejo dos recursos naturais e muitas outras atribuições (SNOWDON, 1999).

Para estudar o comportamento animal, basta ser curioso, ter interesse em conhecer uma infinidade de diferentes espécies e libertar-se da ideia de humanizar o comportamento dos animais, pois o observador não deve ser influenciado pela sua própria avaliação do que está ocorrendo, mas deve preocupar-se em registrar tudo (CARTHY, 1980). Uma vez que, os animais podem exibir comportamentos nos quais deixam de realizar atividades que envolvem movimentações ou deslocamentos, como por exemplo hibernar ou fingir-se de morto, comportamento este denominado tanatose, o qual é utilizado pela perereca Hyla geografica para enganar seus predadores (DEL-CLARO, 2004).

Questões são realizadas, hipóteses e previsões são levantadas para compreender o que é observado. Um dos comportamentos mais instigantes dos animais refere-se à organização social destes. Como e por que vivem em grupos ou isolados? Quais fatores influenciam as espécies nestas formas organizacionais? Para responder tais indagações é preciso abster-se da ideia de que o objetivo de qualquer ser vivo é garantir que o maior número possível de cópias de seus genes permaneça ao longo das gerações.

\section{ORGANIZAÇÃO SOCIAL: UM INSTIGANTE ESTUDO}

Em decorrência da ampla diversidade animal é evidente a existência de variados estilos de vida entre as espécies. Considerando que os indivíduos de uma mesma espécie necessitam dos mesmos recursos ambientais para sobreviver, e que o objetivo de todo ser vivo é garantir a perpetuidade da espécie, faz-se necessário aprender a conviver com seus semelhantes em prol do bem comum. Com essa constatação, percebe-se a fundamental influência do ambiente para com as organizações sociais.

A expressão da organização social se refere às populações e não aos indivíduos e define a natureza das interações entre os membros de uma espécie. Em alguns casos, a exemplo dos diversos insetos sociais, a organização social é bastante rígida e específica da espécie. Nos vertebrados é um fenômeno muito mais dinâmico e pode variar de acordo com as mudanças das condições ambientais e do grupo (MANNING, 1977). Com isso, de uma maneira mais abrangente, entende-se por comportamento social a interação de dois ou mais indivíduos, ou a influência de um indivíduo sobre o outro (DETHIER, 1988), incluindo desde aqueles que interagem apenas para o acasalamento, até os que permanecem em colônias a vida inteira.

Comparações entre espécies sugerem que alimento e predadores sejam os dois principais fatores ambientais que exercem influência sobre o tamanho do grupo 
(KREBS, DAVIES, 1996). Sendo assim, uma das maiores vantagens de viver em grupos sociais é a proteção contra predadores (CARRANZA, 1994), pois, para muitos predadores, o sucesso depende da surpresa: se a vítima é alertada precocemente durante um ataque, a chance de sucesso do predador é pequena (KREBS, DAVIES, 1996). Em um grupo, a chance de algum indivíduo perceber a aproximação de um predador, é maior, considerando que quatro olhos vigiam mais do que dois (CARRANZA, 1994). Com isso, a taxa de vigilância aumenta quando comparada com indivíduos solitários. Como por exemplo, quando um grupo de aves está se alimentando e um predador se aproxima. A primeira ave a vê-lo emite um som específico e o bando imediatamente levanta voo. A partir disso, percebe-se que um indivíduo sozinho precisa se alimentar e vigiar ao mesmo tempo, necessitando dividir o seu tempo para as duas atividades, consequentemente, alimentando-se menos. Dessa forma, à medida que o tamanho do grupo aumenta, cai a proporção de tempo que cada animal despende olhando em redor, e aumenta o número total de animais vigilantes (DEAG, 1981 ; KREBS; DAVIES, 1996).

Os pesquisadores Krebs e Davies (1996) apontam uma questão interessante sobre a possibilidade de um indivíduo trapacear em um grupo, onde poderia apenas alimentarse, considerando que todos os demais estariam vigiando, seguido por uma possível explicação do motivo porque tal comportamento não é selecionado:

A questão de como os indivíduos em um grupo vigiam é complicada pelo fato de que, em um grupo grande, onde a vigilância total está no valor máximo de $100 \%$, valeria a pena um indivíduo trapacear, gastando todo seu tempo de cabeça baixa alimentando-se. $\mathrm{O}$ trapaceiro não perde nada em termos de vigilância, porque outros estão ocupados vigiando enquanto ele ganha tempo extra para se alimentar. Não se sabe como este tipo de trapaça não evolui, mas uma sugestão é a seguinte. Enquanto a estratégia "inocente" de vigiar regularmente, independente do que os outros fazem, seja susceptível à trapaça, um bando formado por indivíduos mais astutos, que não vigiam a menos que tenham visto seus vizinhos fazendo o mesmo, pode ser resistente a trapaceiros (PULLIAM, 1982). A questão mais ampla é que mesmo quando há um benefício para todos com a permanência em um grupo, cada indivíduo tentará obter mais vantagens do que os demais. Em manadas de gazelas de Thompson, o indivíduo que está vigiando quando o predador se aproxima, tem mais chances de escapar (FITZGIBBON, 1989). Aqui há um benefício direto para o indivíduo vigilante, portanto nenhuma seleção a favor da trapaça (KREBS, DAVIES, 1996).

Outra vantagem de viver em grupo é que, em caso de ataque de um predador, o indivíduo reduz as chances de ser a vítima, por simples questão de probabilidade. Este efeito, conhecido como dissolução, é percebido em várias espécies. Como por exemplo, têm-se os cavalos semilivres da França, os quais são frequentemente parasitados por mutucas nos meses de verão. Pesquisas demonstraram que os cavalos que viviam em grupos grandes eram menos atacados pelas mutucas do que aqueles que viviam em grupos pequenos (CARRANZA, 1994). 
Os avestruzes, por exemplo, vivendo em grupos, diluem o impacto de um ataque bem sucedido, ocasionado por leões, porque há uma boa chance de outro indivíduo ser a vítima. Ademais, os predadores raramente atacam um indivíduo em um grupo fechado e sua estratégia mais comum é fazer investidas em direção ao grupo para dispersá-lo, e, então, escolher um animal isolado (MANNING, 1977). Também, diversas espécies de peixes, aves e primatas promovem um efeito de confusão para com seus predadores, movimentando-se rapidamente e ajustando-se em formações que dificultam a captura de um indivíduo do bando (DEAG, 1981; KREBS; DAVIES, 1996).

A vida em grupos também proporciona um maior sucesso reprodutivo (CARRANZA, 1994). Analisando as aves marinhas que nidificam em colônias rochosas, percebe-se que há uma sincronização na postura e eclosão dos ovos. Os predadores, que podem capturar apenas um número limitado de presas por dia, serão "sobrecarregados" pela súbita e breve abundância de ovos e filhotes, de forma que a probabilidade de um ninho ser atacado será reduzida (MANNING, 1977).

Assim como, viver em grupos também otimiza a busca por alimentos. Isso pode ser observado em hienas manchas (Crocuta crocuta), leões e lobos, por exemplo (DEAG, 1981). Só, um lobo não conseguiria abater um alce, nem procurar alimento suficiente e regularmente. Para sobreviver, os lobos necessitam atuar unidos uns com os outros, o que requer divisão de tarefas, entendimento e organização (THEWS, 1977).

O trabalho de Schjelderup-Ebbe apud Buhler (2017) também revela a importância da organização na busca por alimentos em grupos de pardais (Passer domesticus). Para a realização deste estudo, Schjelderup-Ebbe apud Buhler (2017) ofertou a mesma quantidade de alimento, em uma porção única indivisível ou em pequenos fragmentos, de modo aleatório aos animais. O primeiro pardal a chegar ao local de alimentação emitia um chamado especial para avisar os demais, antes de começar a se alimentar, pois, a vantagem de se alimentar em um grupo é o aumento na taxa de vigilância contra predadores. No entanto, isto só acontecia se o alimento estivesse fragmentado. Pois se o alimento fosse indivisível, o custo por recrutamento, em termos de competição por alimento, superaria os benefícios derivados da redução do tempo de vigilância.

Nesse sentido, a vida em grupos também apresenta inconvenientes. Como a velocidade com que o animal ingere o seu alimento. Por exemplo, um grupo de aves, com três a oito indivíduos, que se alimenta de sementes de ervas, leva em torno de 1 a 2 segundos para passar de planta em planta, alimentando-se. Já em grupos com 15 indivíduos, o intervalo pela busca de alimento entre as plantas, demora em torno de 6 segundos, transformando a alimentação em grupo, em algo desvantajoso (CARRANZA, 1994).

Observa-se que, dependendo do tamanho do grupo, as vantagens de viver nele podem tornar-se menores que as desvantagens. No entanto, os animais, entre prós e contras, são capazes de encontrar um ponto de equilíbrio. Para melhor entender como esse comportamento ocorre, muitos pesquisadores vem desenvolvendo modelos matemáticos para definir o tamanho ideal de um grupo, mas todos partem do 
pensamento de que o tamanho ótimo é aquele em que as vantagens e desvantagens se equivalem (CARRANZA, 1994).

Sendo assim, é evidente que algumas características da organização social são impostas pelo ambiente como o próprio tamanho do grupo em que os animais vivem (MANNING, 1977), o qual implica em compartilhar espaço, alimento e qualquer outro recurso, acarretando em conflitos de interesse. Estes conflitos devem ser resolvidos através da interação entre os indivíduos, e a forma mais típica desta interação é a comunicação agonística (CARRANZA, 1994).

O termo comunicação é definido por Deag (1981) como sendo a transferência de informação de um animal para outro, influenciando o comportamento do receptor, por meio de sinais que evoluíram para este fim. Francisco et al. (2017) descrevem agonístico como um termo de origem grega, cujo significado é combate. Assim, a comunicação agonística reflete sobre os mecanismos de combate, incluindo todas as sinalizações e movimentos expressivos suscetíveis a provocar agressões entre os indivíduos do grupo.

Essa tática é boa para animais solitários e territorialistas, mas para a vida em grupos poderia ser desvantajosa. Se os animais derrotados deixassem o bando, este sofreria com as perdas sendo desmembrado pouco a pouco. Dessa forma, o processo evolutivo tenderia a eliminar esta forma de comunicação. No entanto, o que ocorre com animais que vivem em grupos, é que ambos animais interessados em um mesmo recurso, analisam-se, ponderando tamanho, por exemplo, sem iniciar uma luta de imediato. Por fim, o vencedor da disputa ganha o recurso em questão, mas o perdedor não se afasta do bando. Assim, a comunicação agonística é uma importante forma de interação social que regula a vida em grupos, reduzindo as agressões físicas e conseguindo que as relações entre os distintos elementos do grupo sejam mais fluidas (CARRANZA, 1994).

Automaticamente, o indivíduo vencedor da disputa agonística torna-se o dominante, e o perdedor, o subordinado, estabelecendo uma hierarquia na relação. $\mathrm{O}$ trabalho de Buhler (2017) com bandos de aves tornou familiar o conceito de hierarquia. Ele observou que uma ordem de bicadas definida estabeleceu-se nos grupos pequenos de galinhas reunidas em um galinheiro. À medida que as aves disputavam entre si, uma delas destacava-se como dominante, conseguindo afastar todas as outras. Mas uma hierarquia não é imposta apenas com agressão, por isso Deag (1981) prefere utilizar o termo hierarquia agonística, em decorrência de que os animais evitam encarar outros que lhes sejam superiores na hierarquia, resolvendo o confronto sem que ocorra luta, de modo que a submissão perpetua as relações de hierarquia.

Muitas destas relações despertaram nos pesquisadores a curiosidade em conhecer quais são os critérios que margeiam as relações de dominância e subordinação. Após muitos estudos, chegou-se à conclusão que o fator mais importante é o tamanho, seguido pela familiarização pela zona, a idade e finalmente o sexo. Com isso, pode-se afirmar que, ao menos nas espécies estudadas, os machos são mais dominantes não por serem machos, mas sim por serem maiores em tamanho (CARRANZA, 1994). 
Além disso, há sinais de dominância e submissão variados entre os primatas, os quais incluem vocalizações, posturas especiais e expressões faciais. $\mathrm{O}$ macho dominante de um grupo de babuínos, por exemplo, além de ser maior e mais forte, apresenta uma densa pelagem na cabeça e nos ombros, o que lhe acentua o tamanho. Ele intervém impedindo qualquer luta entre os membros do bando, protegendo os indivíduos mais fracos. Quando o bando se desloca, o dominante fica no centro juntamente com os membros jovens e as fêmeas com filhotes. Se o bando for atacado, os machos adultos avançam e se interpõem entre os atacantes e o resto do grupo (CARTHY, 1980).

Em alguns pássaros e mamíferos há uma combinação de hierarquia e território de forma que os animais dominantes ocupam territórios mais amplos ou vivem em áreas preferidas. A exemplo são os sistemas lek de aves como Lyrurus tetrix e o Philomachus pugnox. O lek ou arena é uma área dividida em um conjunto de territórios usados apenas para o acasalamento. Os machos competem por posições desejadas próximas ao centro do lek, onde os territórios são pequenos. Os machos com menor sucesso podem ocupar grandes territórios na periferia do lek, mas as fêmeas são atraídas pelas exibições e grande atividade dos machos das áreas centrais, que obtém maior sucesso no acasalamento (MANNING, 1977).

Em vista disso, percebe-se que tanto dominantes quanto subordinados possuem benefícios e desvantagens nos grupos. Mas é inevitável indagar-se: por que os subordinados não saem dos grupos para viverem sozinhos ou com outros subordinados? Para responder esta questão foram realizados alguns experimentos comparativos. Em um grupo o indivíduo dominante foi removido, e no outro grupo, o dominante permaneceu. $\mathrm{O}$ resultado foi que no grupo sem dominante, a taxa de sobrevivência diminuiu, em decorrência da maioria dos subordinados serem jovens, e não possuírem experiência em buscar alimento e nem defender-se de predadores (CARRANZA, 1994). Portanto, a hierarquia e a dominância nas sociedades assegura a cooperação pacífica do grupo (CARTHY, 1980; DETHIER, 1988).

$\mathrm{Na}$ medida em que os filhotes ficam mais velhos, passam menos tempo com suas mães e interagem cada vez mais uns com os outros, e cujas interações são denominadas brincadeiras (CARTHY, 1980). O comportamento de brincadeira pode-se caracterizar por sequências breves de movimentos exagerados, repetitivos, incompletos que variam de acordo com as espécies, composição de grupo e com o ambiente. Trata-se de um comportamento extremamente dinâmico, que apresenta diferenças entre os sexos, complexa escolha de parceiros e variações durante a ontogenia (DEL-CLARO; PREZOTO, 2003).

No decorrer de brincadeiras com outros, os filhotes parecem não só desenvolver suas habilidades motoras, preparação física para futuras competições sociais ou atividades de caça, auto-avaliação de habilidades competitivas, como também, parece familiarizar-se com outros, através de contato e disputas que persistirão pela vida adulta. Dessa forma, desenvolvem-se ligações entre filhotes de diferentes fêmeas, o que assegura coesão à sociedade. Desse modo, é na infância e na adolescência que são lançadas as bases do 
comportamento adulto envolvido na formação do casal e na cooperação entre adultos (CARTHY, 1980; DEL-CLARO; PREZOTO, 2003).

Wynne-Edwards apud Wilkins (2006) sugere que é comum, ocorrer durante a evolução da vida social, o sacrifício das necessidades egoístas do indivíduo para o benefício do grupo como um todo. Pois somente dessa forma os animais podem viver dos recursos que o seu ambiente fornece. Segundo Carranza (1994) diversas análises comparativas mostram que os caminhos para a sociabilidade não são os mesmos para todas as espécies, de forma que distintas espécies podem chegar a ser sociais por diferentes causas ecológicas.

\section{CONHECER PARA PRESERVAR: A ORGANIZAÇÃO SOCIAL COMO SUBSÍDIO PARA A CONSERVAÇÃO DE ESPPÉCIES}

Cada grupo de animais de uma mesma espécie necessita de uma determinada área para sobreviver. $\mathrm{O}$ tamanho desta área é variável, dependendo do número de indivíduos presentes no grupo, do tamanho corporal dos mesmos, anatomia e hábitos alimentares dos animais, assim como, das características do habitat. A partir do momento que se tem clareza de que as variáveis ecológicas, como a pressão ambiental, a predação, a disponibilidade de alimento, e outras, influenciam o comportamento dos animais, têmse a consciência da importância da preservação e conservação dos ambientes (KREBS; DAVIES, 1996).

Para estabelecer o tamanho do território que determinada espécie necessita, é preciso identificar os animais, registrar os locais que eles percorrem e contabilizar a frequência com que os indivíduos da referida espécie o utilizam. Devido ao tamanho da área ser variável, estabelece-se uma média. Como por exemplo, famílias de gibões da espécie Hylobates lar utilizam um território de, em média, 40 hectares, já pássaros da espécie Parus major utilizam, em média, um território de 8 hectares (DEAG, 1981).

A pesquisa de Jarman (1974) sobre ungulados africanos destacou que a principal correlação da dieta e organização social é com o tamanho corporal, explicando que as espécies de pequeno porte possuíam exigências metabólicas mais altas como frutos e brotos, alimentos estes encontrados em florestas, esparsamente distribuídos, de modo que as espécies pequenas são forçadas a uma vida solitária. No entanto, as espécies maiores consomem alimentos de baixa qualidade, mas em grandes volumes, encontrando alimento nas planícies. No momento em que ungulados de grande porte se deparam com predadores, não tem onde se esconder nas planícies abertas e, como alternativa, permanecem em relativa segurança em grandes manadas ou fogem.

Com isso, conhecer a biologia das espécies e seu comportamento espontâneo no ambiente natural é fundamental para sua conservação (CODENOTTI, 1997). Nesse sentido, Martinez e Prestes (2008), explanam que Amazona pretrei, a qual trata-se de uma espécie de ave migratória, realiza maior agregação populacional durante o 
período de amadurecimento das sementes de Araucaria angustifolia, onde se alimenta, principalmente na região sudeste de Santa Catarina. Dessa forma, as principais medidas conservacionistas para evitar o declínio populacional de $A$. pretrei são: preservar as matas nativas remanescentes, onde a ave encontra condições de nidificação e alimentação, com destaque a $A$. angustifólia; aumentar o grau de proteção dos atuais locais de nidificação e realizar campanhas de educação ambiental. Uma vez que a captura de filhotes também se faz de uma ameaça à sobrevivência da espécie (PRESTES; MARTINEZ, 1997).

Também, muitas espécies são indicadoras da qualidade do ambiente, como a lontra Lontra longicaudis, a qual demonstra grande sensibilidade à poluição e destruição de ambientes aquáticos. Pois, segundo Blacher (1989), esta espécie estava amplamente distribuída por todo território brasileiro, exceto na região nordeste, e atualmente sofre um acentuado declínio em vista da degradação ambiental. Em vista à conservação desta espécie, existem iniciativas em projetos, as quais buscam resgatar nas crianças os valores éticos e estéticos inerentes à conservação da natureza, através da educação ambiental nas escolas.

A expressão educação ambiental foi utilizada pela primeira vez na GrãBretanha, em 1965, na Conferência de Keele, na qual educadores confiaram que a dimensão ambiental deveria ser parte da educação de todos os cidadãos. Uma vez que, principalmente a partir da Revolução Industrial, as relações entre os humanos e o ambiente foram mudando, num processo crescente de dominação e exploração, desencadeando em um acelerado processo de degradação ambiental. Com isso, a partir de 1968, o ambiente começou a ser tratado como algo mais do que um recurso natural, isto é, passou a ser visto com enfoque social, econômico, cultural e político, iniciando uma percepção mais ampla, na qual a educação ambiental é um processo interdisciplinar em constante construção (FOSCHIERA, 2002).

Desse modo, acredita-se que a educação ambiental nas escolas seja um importante caminho à conservação das espécies, pois na vivência diária em uma instituição escolar, as pessoas e os grupos que aí se formam, vão também produzindo novos modos de vida e assim, recriam a cultura geral (PENIN, 2001). Assim como menciona Grosbaum (2001):

\footnotetext{
A escola, por meio de estudos e debates, assume a concepção de ensinoaprendizagem sociointeracionista, quer dizer: o conhecimento é construído pela interação do sujeito com o meio social, e a sua apropriação se efetiva por meio da articulação entre os conceitos cotidianos e científicos. A escola tem o papel central de promover a construção do conhecimento, garantindo ao aluno o acesso ao saber sistematizado e à formação de atitudes e habilidades, proporcionando condições para o exercício da cidadania plena e a construção de uma sociedade mais justa (GROSBAUM, 2011).
}

Para diversificar as aulas, pode-se implementar o estudo do comportamento animal, através das observações nos espaços onde os animais vivem e os estudantes têm acesso como, por exemplo, os parques naturais, as praças da cidade e até as residências 
dos estudantes. Com isso, é possível estimular a compreensão da organização social dos animais, instigando a curiosidade dos alunos sobre os mecanismos e adaptações envolvidos nos diferentes comportamentos que os animais apresentam. Esses conhecimentos podem ser utilizados para os estudos de preservação e conservação dos animais.

Considerando, ainda, o estudo do comportamento animal pode ser muito divertido. Talvez não haja disciplina nas mais distintas áreas do conhecimento mais acessível do que o estudo do comportamento animal. Enquanto um bioquímico ou geneticista precisa de um laboratório muito bem equipado, de técnicos muito bem treinados no uso de equipamentos complexos e muito caros, um biólogo comportamental pode com apenas papel, prancheta, lápis e borracha, desenvolver uma tese de doutorado sobre algo novo, nunca antes descrito ou estudado. Esta realidade é especialmente verdadeira nos países tropicais. No Brasil, por exemplo, onde se encontra a maior biodiversidade do planeta, a maior parte da fauna de invertebrados é ainda totalmente desconhecida da ciência, seja do ponto de vista da sistemática, da zoologia, da genética ou do comportamento (DEL-CLARO, 2004).

Espécies carismáticas como o lobo guará Chrysocyon brachyurus que despertam o afeto do público geral, podem ser utilizadas pelos conservacionistas para demonstrar para as pessoas a conexão entre uma espécie carismática, as outras espécies, o homem e o ambiente como um todo (PRIMACK, 2001), utilizando as palavras de Carvalho Junior do Projeto Lontra: "Somos todos energia, distribuídos em níveis tróficos, relacionadas por simbiose. $\mathrm{O}$ um no todo, o todo no um. Eis o legado às gerações futuras, garantir a incrível biodiversidade da qual fazemos parte" (PROJETO, 2017).

\section{CONSIDERAÇÕES FINAIS}

A Etologia trata-se de um estudo multidisciplinar, abrangendo desde a anatomia dos animais, suas variadas fisiologias e até as relações ecológicas que estes participam. No entanto, o indivíduo que se interessa por estudar o comportamento animal, descobre, no ato de suas observações, que o caminho para encontrar o resultado é tão encantador quanto a descoberta conclusa.

Nesse ínterim, está a fascinante busca por compreender sobre a organização social dos animais. Uma vez que os variados arranjos populacionais, instigantes aos olhares humanos, apresentam-se em perfeita harmonia no ambiente em que estão inseridos. Porquanto, entende-se que é de fundamental importância conhecer o melhor possível uma espécie, para estabelecer ações que contribuam para a sua conservação, acompanhada da preservação do seu habitat.

Com isso, a educação para a conservação apresenta-se como uma forte aliada para minimizar os efeitos antrópicos prejudiciais à natureza. Ponderando-se que a espécie humana deveria observar e conhecer mais o ambiente no qual está inserido. Pois, sabe- 
se que o sucesso de um determinado grupo de animais está intimamente relacionado com o local onde vive.

\section{REFERÊNCIAS}

BLACHER, C. Projeto de conservação e manejo de mamíferos aquáticos no litoral sul do Brasil. Relatório final 88/89. In: Convenção FBCN/IBAMA, 1989.

BUHLER, Charlotte. A psicologia na vida do nosso tempo. Disponível em: <http:// pt.scribd.com/document/43783534/6976069-Charlotte-Buhler-a-Psicologia-Na-Vida-DoNosso-Tempo> Acesso em: 08 jul, 2017.

CARTHY, J.D. Comportamento animal. 2.ed. São Paulo: EPU, v.14. 1980.

CARRANZA ALMANSA, J. (Coord.) Etología: introducción a la ciencia del comportamiento. Madrid: Universidad de Extremadura, 1994.

CARVALHO, Junior. EKKO Brasil- Disponível em: <http://www.ekkobrasil.org.br/pt_BR / site/index/index/ page/14> Acesso em 08 de jul, 2017.

CHAUVIN, R. A etologia: estudo biológico do comportamento animal. Rio de Janeiro: Zahar, 1977.

CODENOTTI, T.L., Etologia: Culminância e síntese do ensino-pesquisa no estudo do comportamento animal. In: Anais de etologia. São Carlos: Sociedade Brasileira de Etologia, 1997.

DEAG, J.M. O comportamento social dos animais. São Paulo: EPU, v. 26. 1981.

DEL-CLARO, K. Comportamento animal: uma introdução à ecologia comportamental. Jundiaí: Livraria Conceito, 2004.

DEL-CLARO, K; PREZOTO, F. As distintas faces do comportamento animal. Jundiaí: Livraria Conceito, 2003.

DETHIER, V.G. Comportamento animal. São Paulo: Edgar Blücher, 1988.

ENCONTRO ANUAL DE ETOLOGIA, 15, 1997, São Carlos. Anais de etologia. São Carlos: Sociedade Brasileira de Etologia, 1997.

ENCONTRO ANUAL DE ETOLOGIA, 9, 1991, Florianópolis. Anais de etologia. Florianópolis: Universidade Federal de Santa Catarina, 1999.

FRANCISCO, S. et al. Etologia: sistema agonístico. [artigo científico]. Disponivel em: <http://pt.scribd.com/doc/40338896/SISTEMA-AGONISTICO-final> Acesso em: 08 jul, 2017.

FOSCHIERA, E. M. Educação ambiental e Desenvolvimento: Projeto Pró-Guaíba na Escola. Passo Fundo: UPF, 2002. 
GROSBAUM, M. W. Como promover o sucesso da aprendizagem do aluno e sua permanência na escola?. In: Pro gestão. MACHADO, M. A. M. (coord.). Módulo IV. Brasília: CONSED, 2001.

KREBS, J.R; DAVIES.N.B. Introdução à Ecologia Comportamental. São Paulo: Atheneu. 1996.

JARMAN, P.J. The social organization of antelope in relation to their ecology. In: (Coord). Animal Behaviour. 215-267. 1974.

LORENZ, K. Os fundamentos da etologia. São Paulo: UNESP, 1995.

MANNING, A. Introdução ao comportamento animal. Rio de Janeiro: LTC, 1977.

MARTINEZ, J. PRESTES, N.P. (Org.). Biologia da conservação: estudo de caso com o papagaio-charão e outros papagaios brasileiros. Passo Fundo: Universidade de Passo Fundo, 2008.

PENIN, Sonia Teresinha de Sousa. Como articular a função social da escola com as demandas da comunidade? In: Progestão. MACHADO. M. A. M (coord.). Módulo 1. Brasília: CONSED, 2001.

PRESTES, N. P.; MARTINEZ, J. Ecologia e Conservação de Amazona pretrei. In: ENCONTRO ANUAL DE ETOLOGIA, 15, 1997, São Carlos. Anais... São Carlos: Sociedade Brasileira de Etologia, 1997. p. 211-222.

PRIMACK, R. B.; RODRIGUES, E. Biologia da conservação. Londrina: Planta, 2001.

PROJETO Lontra. Disponível em: <http://www.ekkobrasil.org.br/pt_BR/site/index/index/ page/14>. Acesso em: 08 jul, 2017.

RUWET, J. C. Etología: biologia del comportamiento.Barcelona: Herder, 1975.

SNOWDON, C. T. O significado da pesquisa em comportamento animal. Disponível em: <http://www.scielo.br/scielo.php > Acesso em: 08 jul, 2017.

THEWS, K. Etologia: a conduta animal, um modelo para o homem?. São Paulo: Círculo do Livro, 1977.

WALLACE, R. A. Sociobiologia: o fator genético. São Paulo: IBRASA, 1985.

WILKINS, J. Evolução e Filosofia: uma introdução. Reducionismo e Evolução. In: Projeto Evoluindo - Biociência.org. Trad.: LORENZON, F. 2006. Disponível em: <http://www. evoluindo.biociencia.org.br> Acesso em: 08 jul, 2017. 